\title{
Excessive daytime sleepiness and adherence to antihypertensive medications among Blacks: analysis of the counseling African Americans to control hypertension (CAATCH) trial
}

\author{
This article was published in the following Dove Press journal: \\ Patient Preference and Adherence \\ II March 2014 \\ Number of times this article has been viewed
}

\author{
Natasha J Williams' \\ Girardin Jean-Louis' \\ Abhishek Pandey² \\ Joseph Ravenell' \\ Carla Boutin-Foster ${ }^{3}$ \\ Gbenga Ogedegbe' \\ 'Center for Healthful Behavior \\ Change, Division of Internal Medicine, \\ NYU Medical Center, New York, \\ ${ }^{2}$ Department of Family Medicine, \\ SUNY Downstate Medical Center, \\ Brooklyn, ${ }^{3}$ Center of Excellence in \\ Disparities Research, Weill Cornell \\ Medical College, New York, NY, USA
}

\begin{abstract}
Background: Excessive daytime sleepiness (EDS) often occurs as a result of insufficient sleep, sleep apnea, illicit substance use, and other medical and psychiatric conditions. This study tested the hypothesis that blacks exhibiting EDS would have poorer self-reported adherence to hypertensive medication using cross-sectional data from the Counseling African-Americans to Control Hypertension (CAATCH) trial.
\end{abstract}

Methods: A total of 1,058 hypertensive blacks (average age $57 \pm 12$ years) participated in $\mathrm{CAATCH}$, a randomized controlled trial evaluating the effectiveness of a multilevel intervention for participants who receive care from community health centers in New York City. Data analyzed in this study included baseline sociodemographics, medical history, EDS, and medication adherence. We used the Epworth Sleepiness Scale, with a cutoff score of $\geq 10$, to define EDS. Medication adherence was measured using an abbreviated Morisky Medication Adherence scale, with a score $>0$ indicating nonadherence.

Results: Of the sample, $71 \%$ were female, $72 \%$ received at least a high school education, $51 \%$ reported a history of smoking, and 33\% had a history of alcohol consumption. Overall, $27 \%$ of the participants exhibited EDS, and 44\% of those who exhibited EDS were classified as adherent to prescribed antihypertensive medications. Multivariable logistic regression analysis, adjusting for effects of age, body mass index, sex, education, and smoking and drinking history indicated that participants who exhibited EDS were more than twice as likely to be nonadherent (odds ratio $2.28,95 \%$ confidence interval $1.42-3.67, P<0.001$ ).

Conclusion: Analysis of the CAATCH data showed a high prevalence of EDS among hypertensive blacks. EDS is a significant predictor of nonadherence to prescribed medications for hypertension. These findings point to a modifiable variable that can be targeted in future interventions focusing on medication adherence.

Keywords: excessive daytime sleepiness, hypertension, medication adherence, blacks

\section{Introduction}

Hypertension affects more than 70 million people in the US and is one of the leading risk factors for cardiovascular morbidity and mortality. ${ }^{1-3}$ Current treatment regimens are effective in controlling hypertension, leading to a decrease in cardiovascular-related events, including stroke and premature death. ${ }^{1}$ According to the Seventh Report of the Joint National Committee on Prevention, Detection, Evaluation, and Treatment of High Blood Pressure, 69\% of hypertensive individuals fail to achieve the recommended blood pressure (BP) goal $(<140 / 90 \mathrm{mmHg}){ }^{1,4}$ While blacks are prescribed antihypertensive medications at nearly the same rates as non-Hispanic whites,
Correspondence: Girardin Jean-Louis Center for Healthful Behavior Change, Department of Population Health, New York University School of Medicine, 227 East 30th St, 6th Floor, New York, NY 10016, USA

$\mathrm{Tel}+\mathrm{I} 64650 \mathrm{I} 2623$

Fax + I 2122634201

Email girardin.jean-louis@nyumc.org 
disparities persist in terms of overall disease management. The evidence shows that only $52 \%$ of blacks achieve the recommended BP control, ${ }^{5}$ which is closely related to medication adherence. A large, representative, prospective cohort study of adults aged 45 years and older found that blacks had worse medication adherence compared with whites $(67.0 \%$ versus $33 \%, P<0.0001)$ using the Morisky Medication Adherence scale. ${ }^{6}$ Together, these findings may explain in part why blacks experience worse cardiovascular health outcomes.

Several studies have investigated the multifaceted role of patient adherence, including age, socioeconomic status, knowledge, attitudes, beliefs, and perceptions, as well as factors including perceived self-efficacy, patient-provider communication, and access to health care. ${ }^{7-11}$ One important but overlooked factor is the role of excessive daytime sleepiness (EDS).

EDS, the main symptom of sleep-disordered breathing, has been estimated to affect up to $37 \%$ of the adult US population. ${ }^{12}$ Importantly, EDS is often chronic, lasting for more than a year in individuals with moderate or severe sleepiness. ${ }^{13}$ It often occurs as a result of insufficient sleep, sleep apnea, illicit substance use, depression, cancer, and other medical conditions. ${ }^{14}$ Of interest is the evidence that supports EDS as an independent risk factor for hypertension. ${ }^{15-19}$ Indeed, there is extensive literature on risk factors for daytime sleepiness, including obesity, age, physical activity, and alcohol use, ${ }^{14,20}$ all of which are known risk factors for hypertension. It is plausible that daytime sleepiness could lead to poor medication adherence. To date, no studies have examined the role of EDS in poor medication adherence among hypertensive patients. This is particularly important for blacks, who tend to report inadequate sleep (short and long sleep durations), obstructive sleep apnea, and overall poor sleep quality. ${ }^{21-23}$

Identifying the complex role of medication adherence, particularly in the context of sleep, could prove useful in designing BP control interventions for blacks. In this crosssectional study, we analyzed data to test the hypothesis that individuals who exhibit EDS would have poorer self-reported adherence to antihypertensive medication. The participants were from the Counseling African Americans to Control Hypertension $(\mathrm{CAATCH})$ trial. The study is registered at clinicaltrials.gov (NCT00233220). ${ }^{24}$

\section{Materials and methods CAATCH trial}

The CAATCH trial is a group randomized control trial comparing a motivational interviewing-based intervention with usual care to improve BP control among hypertensive blacks who receive care in community health care centers. From 2006 to 2009, a total of 1,058 individuals (mean age $46.75 \pm 16.23$ years) were recruited from 30 community health care centers in the New York City metropolitan area. The community health care centers were eligible if at least $25 \%$ of their patients self-identified as black or African-American. ${ }^{25}$ For this secondary data analysis, we focused on baseline sociodemographic and clinical characteristics of CAATCH trial participants. The study methodology and design have been reported previously. ${ }^{25}$

\section{Procedures}

Participants were eligible for the study if they met the following inclusion criteria: self-identify as black or AfricanAmerican, English speaking, at least 18 years of age, receiving care at a participating community health care center for at least a 6-month period, diagnosis of hypertension and uncontrolled BP at the last office visit (BP $\geq 140 / 90 \mathrm{mmHg}$ ), taking at least one antihypertensive medication, and having uncontrolled BP (systolic BP $\geq 140 \mathrm{mmHg}$ or diastolic BP $\geq 90 \mathrm{mmHg}$ ) at the time of consent. BP was measured using an automated oscillometric validated BP monitor (BpTRU $^{\circledR}$, Smiths Medical MDPM, Waukesha, WI, USA). Excluded from the study were patients who were not fluent in English, had an arm circumference $>42 \mathrm{~cm}$, were participating in other hypertension-related trials, were using home BP monitoring, had cognitive impairment as measured by the Mini-Mental State Examination, were unable to complete screening and baseline assessments, and were unwilling or unable to provide written consent. Trained research assistants explained the goals of the study to the participants and obtained baseline clinical and sociodemographic data. ${ }^{26}$

\section{Measurements}

\section{Daytime sleepiness}

We used the Epworth Sleepiness Scale to assess the severity of daytime sleepiness. This is a self-reported eight-item questionnaire using a Likert-type scale in which the respondent indicates a number ranging from 0 (would never doze or sleep) to 3 (indicating a high chance of dozing or sleeping) based on a given situation including sitting and reading, watching television, or sitting and talking to someone. Respondents who scored greater than 10 would be considered sleepy. Validation studies show satisfactory test-retest reliability $(R=0.82)$ and a Cronbach's alpha of $0.88 .^{27}$

\section{Medication adherence}

Medication adherence was assessed using the Morisky Medication Adherence scale, a validated and reliable measure of 
adherence to medication. ${ }^{28}$ Participants responded "yes" or "no" to the following questions: Do you ever forget to take your medicine? Are you careless at times about taking your medicine? Do you sometimes stop taking your medicine when you are feeling well? When you feel worse due to the medicine, do you stop taking it? Adherence was measured on a scale of 0 to 4 . Respondents who scored greater than 0 would be considered nonadherent. The scale has a Cronbach's alpha of 0.90 and has been used with similar samples. ${ }^{28}$

\section{Statistical analysis}

We used frequency distribution and measures of central tendency to describe sociodemographic factors and the overall health risk profile of the sample. We used multiple logistic regression analysis to assess for an association between EDS and medication adherence, adjusting for effects of age, sex, employment, education, body mass index, and smoking and drinking history. All analyses were conducted using Statistical Package for the Social Sciences version 20 software (SPSS Inc., Armonk, NY, USA). All participants provided written consent and the study was approved by the New York University Medical Center Institutional Review Board.

\section{Results}

Of the sample, $71 \%$ were female, $72 \%$ had received at least a high school education, $51 \%$ reported a history of smoking, and $33 \%$ reported a history of alcohol consumption. The average participant had a systolic BP of $144 \pm 29 \mathrm{mmHg}$ and a diastolic BP of $86 \pm 19 \mathrm{mmHg}$. Mean total cholesterol, triglyceride, and glucose levels were $194 \pm 32 \mathrm{mg} / \mathrm{dL}, 122 \pm 71 \mathrm{mg} / \mathrm{dL}$, and $113 \pm 48 \mathrm{mg} / \mathrm{dL}$, respectively. Overall, $27 \%$ of participants exhibited EDS, and $44 \%$ of those who exhibited EDS were classified as being adherent to prescribed antihypertensive medications.

Table 1 shows patient characteristics on the basis of adherence status. There were no significant differences

Table I Adherence status by sociodemographic characteristics and health risks

\begin{tabular}{llll}
\hline Variable & \multicolumn{2}{l}{ Adherence status } & P value \\
\cline { 2 - 3 } & Adherent & Nonadherent & \\
\hline Age (mean \pm SD) & $55 \pm 12$ & $60 \pm \mathrm{II}$ & $<0.00 \mathrm{I}$ \\
BMI (mean \pm SD) & $34 \pm 8$ & $32 \pm 6$ & 0.004 \\
Female sex \% & 72 & 72 & 0.800 \\
Employed \% & 39 & 28 & 0.001 \\
$\geq$ high school \% & 37 & 38 & 0.017 \\
Alcohol history \% & 37 & 26 & 0.001 \\
Smoking history \% & 55 & 46 & 0.008 \\
\hline
\end{tabular}

Note: Mean \pm SD and (\%) is reported.

Abbreviations: BMI, body mass index; SD, standard deviation. by sex. However, when examining other sociodemographic variables and health risks, we found that those who were adherent were more likely to be employed, have at least a high school education, be less likely to report a history of drinking, but be more likely to report a history of smoking. As shown in Table 2, our logistic regression analysis indicated that there was a two-fold increase in the odds of being nonadherent among individuals who exhibited EDS (odds ratio 2.28, 95\% confidence interval 1.42-3.67, $P<0.001)$. Of note, age was a significant contributing factor in the model.

\section{Discussion}

Our study provides evidence of a relationship between EDS and medication adherence in hypertensive blacks. One in four participants exhibited EDS, and individuals who exhibited EDS were nearly twice as likely to be nonadherent. The reported EDS is consistent with other large-scale population studies on the prevalence of EDS in the US population. ${ }^{12}$ Similarly, the adherence rates are consistent with other studies of black hypertensive patients, with nearly one half classified as being nonadherent. ${ }^{29}$

Our findings are also consistent with a previous study of adult patients with heart failure showing that nonadherence to prescribed medication was significantly higher among individuals who experienced sleepiness using an Epworth cutoff score of $\geq 6 .^{30}$ The exact mechanisms underlying such associations are not entirely understood. The authors of the aforementioned study concluded that the association between sleepiness and adherence might be explained by cognitive impairment. Cognitive impairment might not have played a significant role in our study, because we included only individuals who were unimpaired. Conceivably, the overall disease burden might be an explanatory factor, given that patients with hypertension often have several comorbid conditions, including diabetes and obesity. ${ }^{31}$ However, we

Table 2 Associations of sociodemographic characteristics and risk factors with EDS and adherence

\begin{tabular}{llll}
\hline Variable & OR & $\mathbf{C l}$ & $\mathbf{P}$ \\
\hline Sleepy & 2.28 & $1.42-3.67$ & $<0.001$ \\
Age & 0.97 & $0.95-0.99$ & $<0.001$ \\
BMI & 1.02 & $1.00-1.10$ & 0.110 \\
Sex & 1.13 & $0.71-1.80$ & 0.606 \\
Employed & 1.41 & $0.90-2.22$ & 0.140 \\
Education & 0.92 & $0.75-1.06$ & 0.205 \\
Alcohol use & 1.29 & $0.74-1.90$ & 0.468 \\
Smoking & 1.34 & $0.86-2.10$ & 0.195 \\
\hline
\end{tabular}

Abbreviations: BMI, body mass index; EDS, excessive daytime sleepiness; OR, odds ratio, $\mathrm{Cl}$, confidence interval. 
should note that mixed results have been reported, with some studies finding patients with fewer comorbidities are more likely to be adherent, and others finding that patients with a higher number of cardiovascular-related comorbidities are more likely to be adherent. ${ }^{32-34}$

In our analysis, sex was not related to adherence status. In another study utilizing the National Health and Nutrition Examination Survey (1999-2004), men had better BP control than non-Hispanic black women (51.1\% versus $38.8 \%) .{ }^{35}$ In addition, results from initial analysis of another study ${ }^{36}$ showed no significant sex-based differences. However, when interactions between sex and education were explored, women with lower education were less likely to be adherent than their male counterparts. ${ }^{36}$

The results of our study have a number of clinical implications that must be addressed. First, they suggest that health care providers should screen hypertensive patients for sleep-related disorders, particularly EDS. One such screening tool is the Epworth Sleepiness Scale, which is a relatively easy survey that can be self-administered. Other validated self-administered tools are available as well. If necessary, health care providers should organize referral for a sleep study to ascertain the presence of obstructive sleep apnea, a well known independent risk factor for hypertension. ${ }^{17-19}$ In either case, this must be done in a culturally and linguistically appropriate manner when targeting minority communities. Second, overall management of hypertension should include newly identified comorbid conditions including sleep-related problems and not solely the traditional conditions like diabetes and chronic kidney disease. Third, behavioral interventions that seek to address adherence status should include adherence to both prescribed sleep and hypertension regimens. Finally, studies may also wish to look at mechanistic factors that may be common to both daytime sleepiness and adherence, such as stress, especially in low-income communities such as the ones sampled in this study. ${ }^{37}$

Our study has some limitations, including the use of subjective data to measure sleepiness and medication adherence. First, the subjective nature of the data may underestimate the prevalence of EDS, which is a strong predictor of obstructive sleep apnea in this population. ${ }^{37,38}$ However, the data collected in this study do not allow us to determine such associations. Indeed, obstructive sleep apnea is prevalent among hypertensive patients; unique to this report is that sleep-related problems and symptoms in the absence of a sleep disorder could contribute to medication adherence. Second, we used self-reported medication adherence. Future studies should consider valid and reliable objective measures of medication adherence, which could prove useful in obtaining more accurate assessments. ${ }^{11}$ Finally, the findings are limited to a specific population, ie, low-income blacks, so are not representative of the entire US adult population. Despite these limitations, we believe that our findings add to the growing body of literature linking sleep and hypertension.

\section{Conclusion}

Overall, patient nonadherence continues to represent a significant public health burden. Our findings suggest that multifaceted and innovative interventions coupled with traditional risk factors could facilitate medication adherence among blacks.

\section{Acknowledgment}

This research was supported by funding from the National Institutes of Health (R25HL105444, K24HL111315, R01HL095799, and R01MD004113).

\section{Disclosure}

The authors report no conflicts of interest in this work.

\section{References}

1. Chobanian AV, Bakris GL, Black HR, et al. The Seventh Report of the Joint National Committee on Prevention, Detection, Evaluation, and Treatment of High Blood Pressure. Hypertension. 2003;42(6):1206-1252.

2. McGruder HF, Malarcher AM, Antoine TL, et al. Racial and ethnic disparities in cardiovascular risk factors among stroke survivors United States. Stroke. 2004;35(7):1557-1561.

3. Hollar D, Agatston AS, Hennekens CH. Hypertension: trends, risks, drug therapies and clinical challenges in African Americans. Ethn Dis. 2004;14(4):S23-S25.

4. Gu QP, Burt VL, Paulose-Ram R, et al. High blood pressure and cardiovascular disease mortality risk among US adults: the Third National Health and Nutrition Examination Survey mortality follow-up study. Ann Epidemiol. 2008;18(4):302-309.

5. Gu Q, Burt VL, Dillon CF, et al. Trends in antihypertensive medication use and blood pressure control among United States adults with hypertension: the National Health and Nutrition Examination Survey, 2001 to 2010. Circulation. 2012;126(17):2105-2114.

6. Muntner P, Halanychi J, Reynolds K, et al. Low medication adherence and the incidence of stroke symptoms among individuals with hypertension: the REGARDS study. J Clin Hypertens. 2011;13(7): 479-486.

7. He J, Muntner P, Chen J, et al. Factors associated with hypertension control in the general population of the United States. Arch Intern Med. 2002;162(9):1051-1058.

8. Charles H, Good CB, Hanusa BH, Chang CCH, Whittle J. Racial differences in adherence to cardiac medications. J Natl Med Assoc. 2003;95(1): 17 .

9. Ogedegbe G, Schoenthaler A, Richardson T, et al. An RCT of the effect of motivational interviewing on medication adherence in hypertensive African Americans: rationale and design. Contemp Clin Trials. 2007;28(2):169-181.

10. Turner BJ, Hollenbeak C, Weiner MG, et al. Barriers to adherence and hypertension control in a racially diverse representative sample of elderly primary care patients. Pharmacoepidemiol Drug Saf. 2009; 18(8):672-681. 
11. Lewis LM. Factors associated with medication adherence in hypertensive blacks: a review of the literature. J Cardiovasc Nurs. 2012;27(3):208-219.

12. National Sleep Foundation. Excessive Daytime Sleepiness, Health, and Safety. Sleep Foundation; 2010. Available from: http://www. sleepfoundation.org. Accessed November 18, 2012.

13. Ohayon MM. Detrimental effects of double occupation on the sleep of students. Sleep. 2011;34:A184.

14. Pagel JF. Excessive daytime sleepiness. Am Fam Physician. 2009;79(5): 391-396.

15. Newman AB, Spiekerman CF, Enright P, et al. Daytime sleepiness mortality and cardiovascular disease in older adults. J Am Geriatr Soc. 2000;48(2):115-123.

16. Colten HR, Altevogt BM, editors. Sleep Disorders And Sleep Deprivation: An Unmet Public Health Problem. Washington DC: National Academies Press; 2006.

17. Ohayon MM, Guilleminault C, Priest RG, Zulley J, Smirne S. Is sleepdisordered breathing an independent risk factor for hypertension in the general population? J Psychosom Res. 2000;48(6):593-601.

18. Lavie P, Herer P, Hoffstein V. Obstructive sleep apnea syndrome as a risk factor for hypertension: population study. $B M J .2000 ; 320(7233)$ : 479-482.

19. Young T, Peppard P, Palta M, et al. Population-based study of sleepdisordered breathing as a risk factor for hypertension. Arch Intern Med. 1997;157(15):1746-1752.

20. Bixler EO, Vgontzas AN, Lin HM, et al. Excessive daytime sleepiness in a general population sample: the role of sleep apnoea, age, obesity, diabetes, and depression. J Clin Endocrinol Metab. 2005;90(8) 4510-4515.

21. Zizi F, Pandey A, Murray-Bachmann R, et al. Race/ethnicity, sleep duration, and diabetes mellitus: analysis of the National Health Interview Survey. Am J Med. 2012;125(2):162-167.

22. Durrence HH, Lichstein LK. The sleep of African Americans: a comparative review. Behav Sleep Med. 2006;4(1):29-44.

23. Redline S, Tishler PV, Hans MG, Tosteson TD, Strohl KP, Spry K. Racial differences in sleep-disordered breathing in African-Americans and Caucasians. Am J Respir Crit Care Med. 1997;155(1):186-192.

24. National Heart, Lung, and Blood Institute (NHLBI). The recruitment status of this study is unknown because the information has not been verified recently. Available from: http://clinicaltrials.gov/show/NCT00233220. NLM identifier: NCT00233220. Accessed November 1, 2013.

25. Ogedegbe G, Tobin JN, Fernandez S, et al. Counseling African Americans to control hypertension (CAATCH) trial: a multi-level intervention to improve blood pressure control in hypertensive blacks. Circ Cardiovasc Qual Outcomes. 2009;2(3):249-256.
26. Schoenthaler A, Allegrante J, Chaplin W, Ogedegbe G. The effect of patient-provider communication on medication adherence in hypertensive black patients: does race concordance matter? Ann Behav Med. 2012;43(3):372-382.

27. Johns MW. Reliability and factor-analysis of the Epworth Sleepiness Scale. Sleep. 1992;15(4):376-381.

28. Morisky DE, Green LW, Levine DM. Concurrent and predictive validity of a self-reported measure of medication adherence. Med Care. 1986;24(1):67-74

29. Fernandez S, Tobin J, Cassells A, Diaz-Gloster M, Kalida C, Ogedegbe G. The counseling African Americans to control hypertension (CAATCH) trial: baseline demographic, clinical, psychosocial, and behavioral characteristics. Implement Sci. 2011;6:100.

30. Riegel B, Moelter S, Ratcliffe S, et al. Excessive daytime sleepiness is associated with poor medication adherence in adults with heart failure. J Card Fail. 2011;17(4):340-348.

31. Schoenthaler A, Ogedegbe G, Allegrante JP. Self-efficacy mediates the relationship between depressive symptoms and medication adherence among hypertensive African Americans. Health Educ Behav. 2007;36(1):127-137.

32. Lagu T, Weiner MG, Eachus S, Tang SSK, Schwartz JS, Turner BJ. Effect of patient comorbidities on filling of antihypertensive prescriptions. Am J Manag Care. 2009;15(1):24-30.

33. Schoenthaler A, Chaplin WF, Allegrante JP, et al. Provider communication effects medication adherence in hypertensive African Americans. Patient Educ Couns. 2009;75(2):185-191.

34. Gu Q, Burt VL, Paulose-Ram R, Dillon CF. Gender differences in hypertension treatment, drug utilization patterns, and blood pressure control among US adults with hypertension: data from the National Health and Nutrition Examination Survey 1999-2004. Am J Hypertens. 2008;21(7):789-798.

35. Braveman J, Dedier J. Predictors of medication adherence for African American patients diagnosed with hypertension. Ethn Dis. 2009;19(4):396-400.

36. Kashani M, Eliasson A, Vernalis M. Perceived stress correlates with disturbed sleep: a link connecting stress and cardiovascular disease. Stress. 2012;15(1):45-51.

37. Strohl KP, Redline S. Recognition of obstructive sleep apnea. Am J Respir Crit Care Med. 1996;154(2 Pt 1):279-289.

38. Jean-Louis G, Magai CM, Cohen CI, et al. Ethnic differences in selfreported sleep problems in older adults. Sleep. 2001;24(8):926-933.
Patient Preference and Adherence

\section{Publish your work in this journal}

Patient Preference and Adherence is an international, peer-reviewed, open access journal focusing on the growing importance of patient preference and adherence throughout the therapeutic continuum. Patient satisfaction, acceptability, quality of life, compliance, persistence and their role in developing new therapeutic modalities and compounds to

\section{Dovepress}

optimize clinical outcomes for existing disease states are major areas of interest. This journal has been accepted for indexing on PubMed Central. The manuscript management system is completely online and includes a very quick and fair peer-review system. Visit http://www.dovepress.com/ testimonials.php to read real quotes from published authors. 